\title{
Atypical presentation of IgG4-related autoimmune pancreatitis - be awake to early detecting subsequent renal involvement: case report and literature review
}

\author{
Agnieszka AP ${ }^{1,2}$, Isabelle Brochériou ${ }^{3}$, Pieter Demetter ${ }^{4}$, Joëlle Nortier ${ }^{1,2}$, Celso Matos ${ }^{5}$ and Myriam Delhaye \\ ${ }^{1}$ Nephrology, Transplantation and Dialysis Department, Cliniques Universitaires de Bruxelles (CUB), Erasme Hospital, Brussels, Belgium \\ ${ }^{2}$ Experimental Nephrology Unit, Faculty of Medicine, Université Libre de Bruxelles (ULB), Brussels, Belgium \\ ${ }^{3}$ Pathology Department, Tenon Hospital, Université Pierre et Marie Curie, Paris 6, Paris, France \\ ${ }^{4}$ Pathology Departments, Cliniques Universitaires de Bruxelles (CUB), Erasme Hospital, Brussels, Belgium \\ ${ }^{5}$ Radiology Departments, Cliniques Universitaires de Bruxelles (CUB), Erasme Hospital, Brussels, Belgium \\ ${ }^{6}$ Gastroenterology Departments, Cliniques Universitaires de Bruxelles (CUB), Erasme Hospital, Brussels, Belgium
}

\begin{abstract}
We report a case of atypical radiological presentation of type 1 autoimmune pancreatitis (AIP) associated with sclerosing cholangitis, corresponding to a recently described systemic disorder named IgG4-related systemic disease (IgG4-RSD). In our patient (a 62 year-old man), magnetic resonance cholangiopancreatography showed atypical stenosis of the main pancreatic duct with upstream dilatation and 2 pseudocysts, unusual in AIP. Pancreatic carcinoma was initially suspected because of a mass on computed tomography and high serum CA19-9 level, but not supported by normal brush cytology of the pancreatic duct. Considering the high serum IgG4 levels and numerous IgG4+ plasma cells in duodenal papillary tissue biopsy, a diagnostic of sclerosing cholangitis and type 1 AIP was retained. Steroid therapy markedly improved clinical, biological and radiological features. Diffusion-weighted magnetic resonance imaging (DW-MRI) DEMONSTRATED cortical nodular lesions in both kidneys. Two years later, biological and radiological relapse was associated with enhanced level of plasma creatinine. As a progressive chronic kidney disease occurred in our case and based on a review of published cases of IgG4-related tubulointerstitial nephritis associated with AIP, we underline the usefulness of DW-MRI for early detection of renal lesions and the importance of biological screening of renal function during the long term follow up of such patients.
\end{abstract}

\begin{abstract}
Abbreviations: AIP: autoimmune pancreatitis, CA 19-9: cancer antigen 19-9, CST: corticosteroids, CT: computed tomography DW-MRI: diffusion-weighted magnetic resonance imaging, ERCP: endoscopic retrograde cholangiopancreatography, FDG-PET: [18F] fluorodeoxyglucose-positron emission tomography, IgG4-RSD: Immunoglobulin G4-related systemic disease, LPSP:lymphoplasmocytic sclerosing pancreatitis, MDZ: methylprednisolone, s-MRCP: Secretinenhanced magnetic resonance cholangiopancreatography, PDZ: prednisolone, PCr: Plasma creatinine, US: ultrasonography, TIN: tubulointerstitial nephritis
\end{abstract}

\section{Introduction}

Type 1 autoimmune pancreatitis (AIP), a distinct form of chronic pancreatic disease is mostly reported in elder men (60 years old), presenting with obstructive jaundice, weight loss, mild abdominal pain and occasionally associated with other autoimmune diseases [1,2] .Imaging of type 1 AIP may mimic pancreatic carcinom [3-6]. According to the revised International Association of Pancreatology [7] and Mayo Clinic HISORt criteria [8], diagnosis of type 1 AIP (or lymphoplasmacytic sclerosing pancreatitis) requires representative radiological finding (diffuse or segmental narrowing of the main pancreatic duct with irregular wall on endoscopic retrograde cholangiopancreatography [ERCP]), serologic markers (elevated levels of gamma-globulins, of IgG and/or of IgG4) and typical histopathological criteria [diffuse lymphoplasmacytic infiltration with numerous interstitial IgG4+ plasma cells (> 10 cells per high-power field), "storiform fibrosis", eosinophils infiltration, focal destruction of pancreatic acini but preserved duct epithelium and lumen, associated with obliterative phlebitis or arteritis. Generally, a marked response to corticosteroid immunosuppressive therapy is observed [9-11]. Actually, type 1 AIP is considered as a prototype manifestation of IgG4-related systemic disease (IgG4-RSD) [11]; a systemic syndrome characterized by mass-forming lesions mainly in exocrine organs (bile duct, gallbladder, retroperitoneum, lacrimal and salivary glands, lung, hypophysis, aorta, lymph nodes and hematological system) that consist of IgG4 positive plasma cells infiltrate and significant fibrosis [12-15].

In 2004, the first cases of IgG4- related tubulointerstitial nephritis (IgG4-related TIN) associated with AIP were independently reported by two groups demonstrating that the kidney could be involved in IgG4-RS [16,17].

Correspondence to: Agnieszka AP, Department of Nephrology, Transplantation and Dialysis, Erasme Hospital, Université Libre de Bruxelles, Route de Lennik 808, B-1070 Brussels, Belgium E-mail: agnieszka.pozdzik@chc.be

Key words: IgG4-related disease, autoimmune pancreatitis, tubulointerstitial nephritis, diffusion-weighted magnetic resonance imaging

Received: August 23, 2016; Accepted: September 26, 2016; Published: September 29, 2016 
We report a case of atypical radiological presentation of type 1 AIP associated with IgG4 sclerosing cholangitis. As two years after relapse of AIP a progressive chronic renal insufficiency occurred, we underline the importance of biological screening of renal function and the usefulness of diffusion-weighted magnetic resonance imaging (DWMRI) for early detection of renal lesions during the long term follow up of such patients.

\section{Case report}

A 62-year-old Caucasian man was admitted in another hospital in August 2005 because of a 3-month history of appetite and weight loss (8 $\mathrm{kg}$ ), foul-smelling greasy diarrhea and general fatigue. The past medical history was unremarkable, with no history of alcohol abuse, drug use or toxic exposure. The physical examination marked by jaundice and the blood tests demonstrated liver cytolysis, cholostasis and elevation of bilirubine and of cancer antigen (CA) 19-9 level (Figure 1).

Abdominal CT showed a mass in the pancreatic head. As despite implantation of a metallic biliary stent, jaundice and pruritus persisted, pancreatoduodenectomy was considered. The patient was referred to our gastroenterology department for a second assessment in September 2005. Abnormal liver function tests (aspartate aminotransferase (AST): $71 \mathrm{IU} / \mathrm{L}(\mathrm{N}<35)$, alanine aminotransferase (ALT): $83 \mathrm{IU} / \mathrm{L}(\mathrm{N}<5)$, alkaline phosphatase (AP): 235 IU/L (N: 56-119), total bilirubin: 6,2 $\mathrm{mg} / \mathrm{dL}(\mathrm{N}<1.2)$ was associated with elevated level of CA 19-9: 1590
$\mathrm{U} / \mathrm{mL}(\mathrm{N}<37)$ and of IgG4: $959 \mathrm{mg} / \mathrm{dL}(\mathrm{N}: 14-126)$. Serum amylase and lipase levels were elevated $(138 \mathrm{IU} / \mathrm{L}(\mathrm{N}<125)$ and $96 \mathrm{IU} / \mathrm{L}(\mathrm{N}<$ 67); respectively). Screening for autoimmune antibodies was negative. Peripheral blood lymphocytes B population was polyclonal. The human leukocytes antigen (HLA) class II haplotype was $\mathrm{DRB} 1^{\star} 07, \mathrm{DRB} 1^{\star} 13$, $\mathrm{DQB1}{ }^{\star} 02, \mathrm{DQB} 1^{*} 03$. Swelling of the pancreatic head with dilated intrahepatic bile ducts was demonstrated by abdominal CT (Figure 2). Secretin-enhanced magnetic resonance cholangiopancreatography (s-MRCP) showed narrowing of the pancreatic duct and dilatation of the upstream main pancreatic duct associated with one cyst located in the duodenal groove and a second one in the tail of the pancreas (Figure 2). Positron emission tomography with [18F] fluorodeoxyglucose (FDGPET) showed significant uptake of FDG limited to the pancreatic head (Figure 2E). Endoscopique retrograde choloangiopancreatography (ERCP) confirmed diffuse narrowing of the main pancreatic duct and segmental substenosis of the distal common bile duct (Figure 3).

The epithelial cells were normal as attested by cytology of intraductal brush (Figure 4A). However, polymorph inflammatory cells (lymphocytes, plasma cells and eosinophils) diffusely infiltrated the duodenal papillary biopsy (Figure 4B). Markedly increased number of IgG4+ plasma cells (intracellular pattern of immunostaining) (>10 cells per high-power field; original magnification x400) (Figure 4C). Contrary to few interstitial CD20+ cells, an enhanced number of CD79 alpha+ and CD138+ cells was observed, reflecting massive infiltration

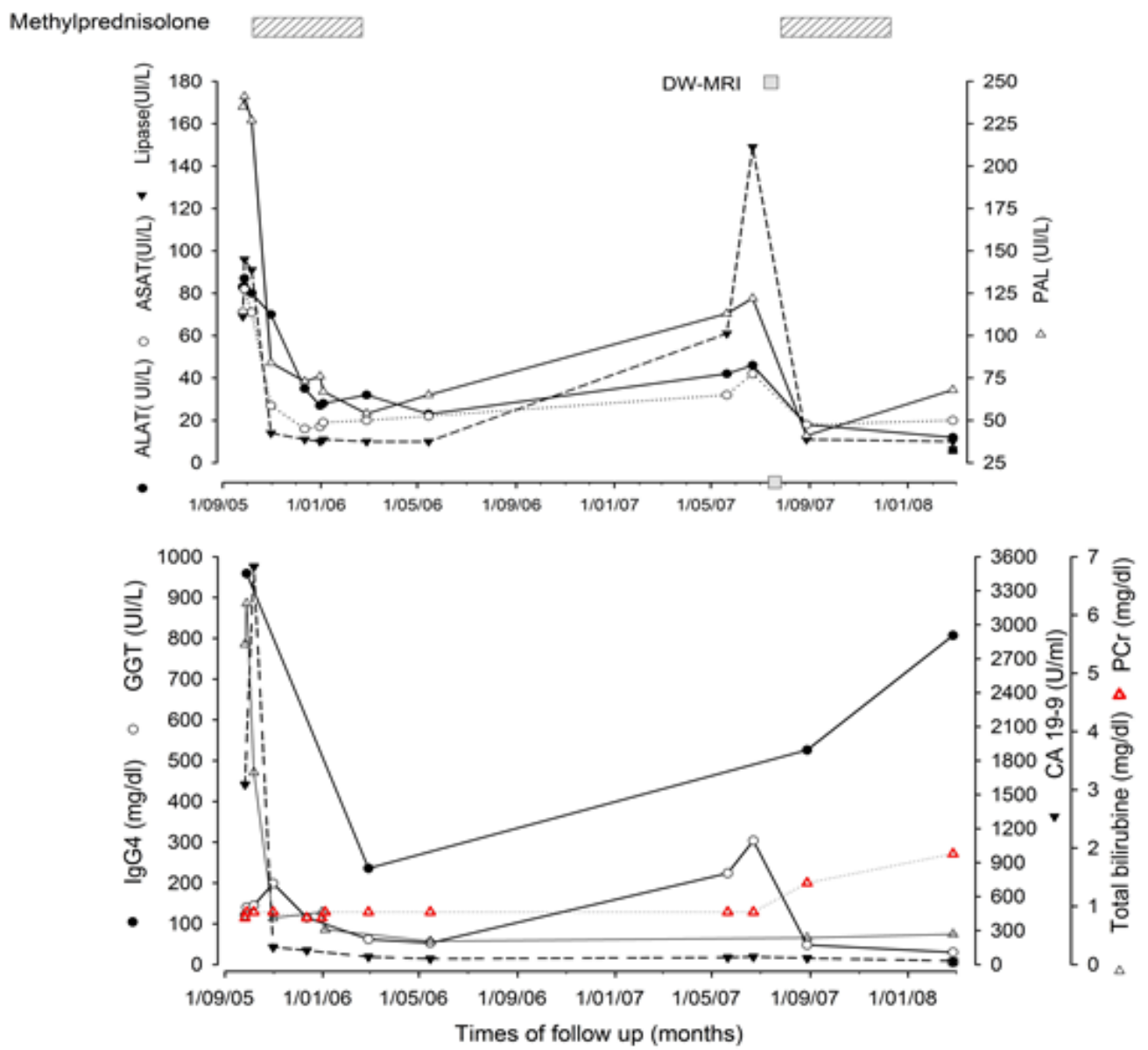

Figure 1. Time-course of serological markers of AIP and periods of immunosuppressive therapy during the follow-up of patient.

(A) Evolution of hepatic and pancreatic enzymes. (B) Time-course of IgG4, GGT, CA 19-9, bilirubine and craetininemia during the follow-up of the patient indicated the periods of immunosuppressive therapy. Pleases not that $(\square)$ represent DW-MRI that demonstrated the presence of bilateral nodular formation in renal cortex few weeks before significant enhancement of plasma ceratinine level (red triangle). 

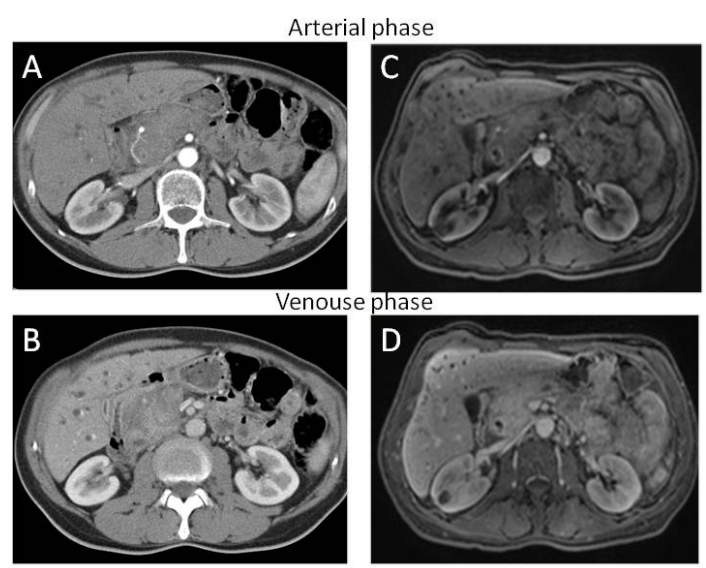

$\mathrm{E}$

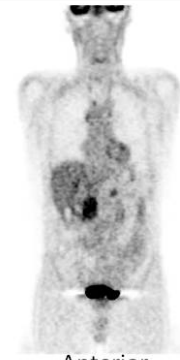

Anterior

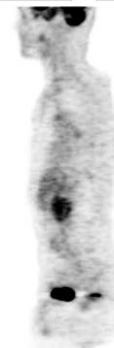

Lateral

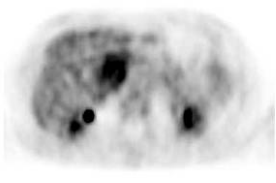

Profil
Figure 2. Abdominal contrast enhanced computed tomography evaluation. (A and C) As compared with the arterial phase, contrast enhanced CT and (B and D) MRI in the portal venous phase showed enlargement of the head of the pancreas and heterogeneous enhancement. The structure of kidneys was normal except for one cyst in the right kidney. (E) Hypermetabolic lesion located in the head of the pancreas identified by $[18 \mathrm{~F}]$ fluorodeoxyglucose-positron emission tomography examination.
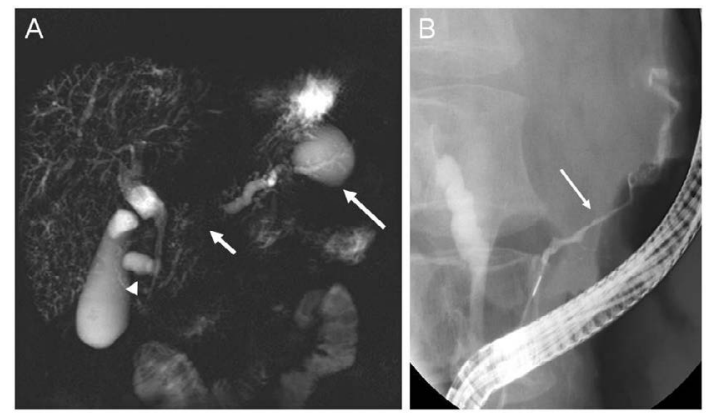

Figure 3. Secretin-enhanced magnetic resonance cholangiopancreatography (s-S-MRCP) and endoscopic retrograde cholangiopancreatography (ERCP) studies. (A) Secretinenhanced S-MRCP showed main pancreatic duct stenosis (short arrow) with upstream dilatation and a pseudocyst in the tail of the pancreas (long arrow). Another pseudocys was observed in the duodenal groove adjacent to the common bile duct (arrowhead). Intrahepatic bile ducts were of irregular caliber and presented multiple strictures, featuring sclerosing cholangitis. (B) ERCP showed a long and incomplete stricture involving the main pancreatic duct (arrow).

by mature plasma cells (Figure 4E-F). Among CD3+ cells, CD4+ cells ( $\mathrm{T}$ helper cells) clearly predominated over CD8+ cells (cytotoxic $\mathrm{T}$ lymphocytes) and CD68+ cells (monocytes/macrophages) populations (Figure 4G-J). Index of cellular proliferation was low (Ki-67 expression) (Figure $4 \mathrm{~K}$ ). Only few interstitial myofibroblasts were identified by alpha-smooth muscles actin immunostaining (Figure $4 \mathrm{~L}$ ).

Methyprednisolone (MDZ) (32 mg/day orally) was started in October 2005 leading to a rapid decrease in serum IgG4 and CA19-9 levels and normalization of liver enzymes, of lipase and total bilirubin levels (Figure 1). After one month, absence of hypermetabolic activity in the head of the pancreas was confirmed by control FDG-PET (Figure 5A). Moreover, significant regression of both pancreatic cysts and marked improvement of pancreatic duct morphology was demonstrated by s-MRCP (Figure 5B). The MDZ was tapered progressively until June 2006. At this moment, renal function was normal (plasma creatinine (PCr) level at $0.9 \mathrm{mg} / \mathrm{dL}(79.6 \mathrm{mmol} / \mathrm{L})$ (Figure 1).

In July 2007, whilst the patient had no symptoms, recurrent increase in serum IgG4 and CA19-9 levels indicated a relapse of the disease. Swelling of the pancreas, with again a mass in the head of the pancreas with upstream main pancreatic duct dilatation and intrahepatic bile duct irregularities and dilatation was confirmed by s-MRCP (Figure 6A). The corticotherapy was restarted (MDZ $32 \mathrm{mg}$ daily) leading to the normalization of amylase levels. At this time, CA19-9 level was nearly normal but serum IgG4 level remained significantly high $(526 \mathrm{mg} / \mathrm{dL})$. Interestingly, as demonstrated by $\mathrm{T} 2$-weighted transvers section, the pancreas was atrophic although multiple hyperintense nodular areas involving cortex and medulla of both kidneys were observed (Figure 6B). Diffusion-weighted MRI showed small nodular hypointense areas of decreased water diffusion in both kidneys (Figure 6C). Arterial phase contrast-enhanced T1-weighted MRI section with fat saturation demonstrated increased uptake in the nodular areas suggesting a proliferative disorder in the kidneys (Figure 6D). In August 2008, renal function deteriorated as demonstrated by progressive increased of PCr from $0.9 \mathrm{mg} / \mathrm{dL}$ to $1.4 \mathrm{mg} / \mathrm{dL}$ [79.6 to $123.8 \mathrm{mmol} / \mathrm{L}$ ] over
A
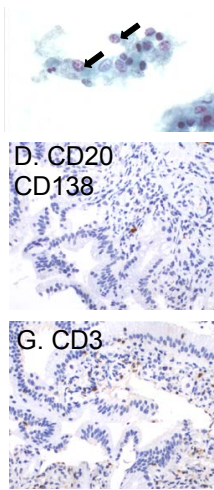

J. CD68 SMA

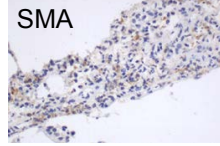

C. $\lg 44$
Figure 4. Cytology obtained by brushing of main pancreatic duct stricture and histological study of duodenal papillary biopsy. (A) Brush cytology showed no atypia in epithelial cells excluding a pancreatic carcinoma (Papanicolau staining, original magnification $\mathrm{x} 400$ ). (B) Tissue sections of duodenal papillary biopsy demonstrated diffuse polymorph interstitial inflammation, containing numerous plasma cells (arrows) and eosinophils (arrow heads) (Hematoxylin\&eosin staining, original magnification x1000). (C) Intracytoplasmic IgG4 expression (perinuclear pattern) in the interstitium of tissue section from duodenal papillary biopsy identified numerous infiltrating IgG4+ plasma cells (C) (Immunoperoxidase staining using monoclonal anti-IgG4 antibody provided form Invitrogen, dilution 1:100; original magnification $\mathrm{x} 1000$ ).

Immunohistochemical phenotyping of inflammatory cells in tissue sections from duodenal papillary biopsy. (D) Few CD20+ cells (immature B cells), (E) several CD79 alpha+ and (F) CD138+ interstitial cells (mature plasma cells) were identified in the duodenal papillary tissue sections. (G) Among CD3+ T cells, (H) obvious CD4+ T cells infiltration was found, however (I) some CD8+ T cells were also observed. (J) Interstitial CD68 positively stained cells identified diffuse infiltration by monocytes/macrophages within the duodenal papillary tissue sections. (K) Ki-67 nuclear expression was found only in some epithelial and interstitial cells reflecting low cellular proliferation index. (L) Cells expressing alphasmooth muscle actin (alpha-SMA) identified few interstitial myofibroblasts in the duodenal papillary tissue sections. These cells are considered as a main cell source of interstitial collagen involved in interstitial fibrosis. (D-L; Immunoperoxidase staining, original magnification D-L x200, for the primary antibodies please see [58] 
A

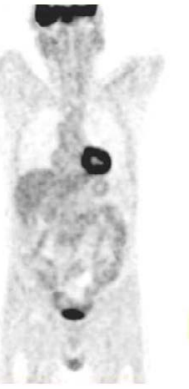

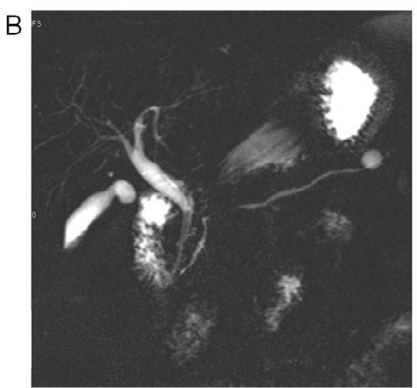

Figure 5. Radiological evolution of $\left[{ }^{18} \mathrm{~F}\right]$ fluorodeoxyglucose-positron emission tomography (FDG-PET) and secretin-enhanced magnetic resonance cholangiopancreatography (s-MRCP) one month after starting of corticoids. (A) FDG-PET follow-up obtained 1 month after the initiation of steroid therapy demonstrated normal FDG uptake in the pancreas. (B) Follow-up s-MRCP obtained 1 month after the initiation of steroid therapy, showed a significant reduction of the caliber and improvement of the main pancreatic duct stricture, decrease in the size of the pseudocyst in the tail, disappearance of the pseudocyst in the duodenal groove and a significant regression of intrahepatic bile ducts cholangitis.
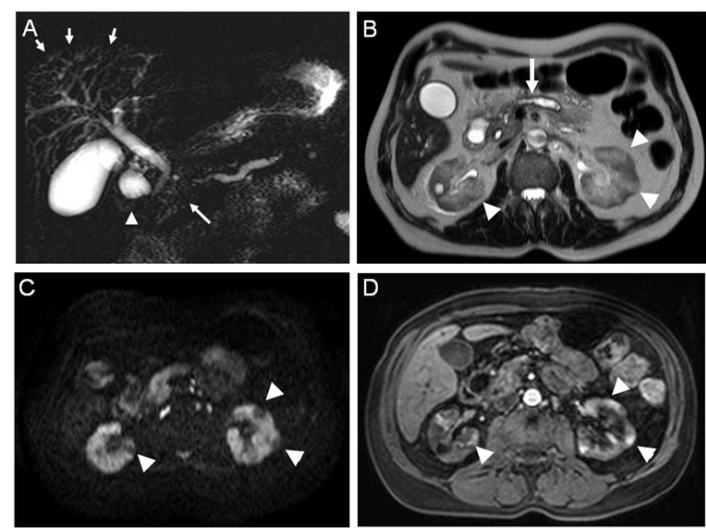

Figure 6. Follow-up s-MRCP obtained at 2 years of follow-up.

(A). Recurrence of main pancreatic duct stenosis (long arrow) and of pseudocyst (arrowhead) in the duodenal groove Intrahepatic bile duct cholangitis is displayed again (short arrows). (B) T2-weighted transverse section at the level of the pancreas and kidneys showed main pancreatic duct enlargement (long arrow) and multiple hyperintense nodular areas involving the cortex and medulla of both kidneys (arrowheads). (C) Diffusionweighted imaging $\left(b=1000 \mathrm{~mm} / \mathrm{s}^{2}\right)$ at the same level than $B$ showed small nodular hypointense areas of increased water diffusion in both kidneys (arrowheads) (D). Arterial phase contrast-enhanced T1-weighted section with fat saturation confirmed increased uptake (arrowheads) in the nodular areas in both renal cortex observed in B and C.

a period of 24 months of follow up but the levels of pancreatic and liver enzymes remained normal (Figure 1). The patient was referred to nephrologists in order to confirm IgG4-related TIN as well as to adjust immunosuppressive therapy and was reported as a case report previously [18]. Written informed consent for use of all data was obtained from patient.

\section{Discussion}

Our case reported here of atypical radiological presentation of AIP type 1 corresponding to a recently described systemic disorder named IgG4-RSD.

In our case, s-MRCP and ERCP showed stenosis of the main pancreatic duct with upstream dilatation and 2 pseudocysts, very unusual in AIP type 1, associated with sclerosing cholangitis. Indeed, a long stricture (1/3 the length of the main pancreatic duct) and lack of upstream dilatation from the stricture $(<5 \mathrm{~mm})$ has been proposed as a key features of AIP on ERCP [19]. Consensus diagnostic protocols of imaging in the diagnosis and management of AIP includes contrast- enhanced CT and MRI for pancreatic parenchymal lesion localization and characterization, ERCP and S-MRCP to assess pancreatic duct involvement. However, ${ }^{18} \mathrm{FDG}$-PET/CT imaging has a valuable role in assessing the involvement of extra-pancreatic sites, staging extent and activity of disease, guiding organ biopsy, and monitoring response to treatment [20].

In pseudotumoral cases, AIP can be misdiagnosed as pancreatic cancer leading to pancreatic resection $[21,22]$. AIP is diagnosed in approximately $2 \%$ to $6 \%$ of patients that undergo pancreatic resection for suspected pancreatic cancer [23]. The suspicion of pancreatic carcinoma (high serum CA19-9 level as well as abdominal CT and ${ }^{18}$ FDG-PET/CT findings) was not supported by normal brush cytology of the pancreatic duct in our patient. Indeed, a consensus statement of International Study Group of Pancreatic Surgery reported that diagnosis of pancreatic head cancer by cholangiopancreatography brushing and percutaneous fine-needle aspiration, as we performed, are highly specific, but poorly sensitive. Aspiration biopsy guided by endoscopic ultrasonography (EUS) has greater sensitivity, but it is highly operator dependent and increase expense [24].

Accordingly to new diagnostic criteria $[25,26]$, high serum IgG4 levels $(135 \mathrm{mg} / \mathrm{dL})$ and the presence of numerous IgG4+ plasma cells (>10 per high-power field) in duodenal papillary tissue biopsy confirmed IgG4-related AIP and IgG4-related cholangitis. Until today, the significance of IgG4 positive plasma cells as well as of CD4 (helper) $\mathrm{T}$ cells and of CD8 (cytotoxic) T cells infiltrating involved organs is unknown, but it is proposed that $\mathrm{T}$ regulatory cells could be involved in the production of IgG4 by mature B cells [11,27]. The antigenic specificity as well as the physiological link between the increased IgG4 level and clinical manifestations still remains unexplained $[11,27]$.

Haplotype $\mathrm{DRB} 1^{\star} 405 / \mathrm{DQB} 1^{\star} 0401$ was not found in this case. Indeed, the mutations of $D R B 1^{\star} 405 / D Q B 1^{*} 0401$ genes has been reported significantly more frequent in patient with AIP as compared to those with chronic calcifying pancreatitis [28]. However, our patient presented haplotype $\mathrm{DQB} 1^{\star} 02, \mathrm{DQB} 1^{\star} 03$ that has been reported significantly associated with the relapse of AIP [28]. Indeed, AIP display a high tendency to relapse in pancreas and biliary tree $(31 \%$ and $56 \%$ of patients, respectively) [29].

Steroid therapy markedly improved clinical, biological and radiological features [11,15]. In IgG4-related AIP and sclerosing cholangitis, the remission is usually obtained by oral PDZ $(0.6 \mathrm{mg} /$ $\mathrm{kg}$ /day during 2-4 weeks, followed by dose tapering of $5 \mathrm{mg}$ every 1-2 weeks) and adapted according to the evolution of the clinical manifestations, the biochemical blood tests and repeated imaging findings [30]. Such a closed pancreatic follow-up is recommended during at least 3 years [31,32].

Two years after a biological and radiological relapse of pancreatitis and cholangitis, our patient developed bilateral cortical nodular lesions in both kidneys followed by progressive increase in PCr level reflecting the renal involvement during disease progression.

Based on our observation, we reviewed all case reports as well as case series of IgG4-related TIN associated with AIP type 1 published in the literature [6,16-18,21,22,33-49]. Articles were selected upon the following criteria: 1) written in English, 2) type 1 AIP was confirmed by biological, radiological and/or immunohistological criteria and 3) the pathological aspects of renal injury were confirmed by IgG4 immunohistochemistry. The clinico-biological, histological and radiological features, the time periods between the AIP diagnosis and 
Agnieszka AP (2016) Atypical presentation of IgG4-related autoimmune pancreatitis - be awake to early detecting subsequent renal involvement: case report and literature review

the alteration of renal function as well as the immunosuppressive therapy used are summarized in Table 1.

From 2004 up to December 2015, we indentified 50 patients (46 men and 4 women) of IgG4-related TIN and AIP corresponding to our review criteria. An average age at the time of evaluation of renal function was 65.0 (min - max: 16 - 84) years. The mean time periods between the AIP diagnosis and the reported alteration of renal function was 25.7 ( $\min$ - max: 0 - 96) months. At the time of renal evaluation, the mean level of $\mathrm{PCr}$ and of IgG4 was 1.1 (min max: $0.74-7.26) \mathrm{mg} / \mathrm{dL}$ and $956(\min -\max : 221-2350) \mathrm{mg} / \mathrm{dL}$ respectively. Significant glomerular proteinuria was associated with

Table 1. Review of published cases of IgG4-related (type 1) AIP and subsequent TIN: main clinical.

\begin{tabular}{|c|c|c|c|c|c|c|c|}
\hline & Sex/Age (years) & $\begin{array}{c}\text { Time } \\
\text { AIP-RF (months) }\end{array}$ & $\begin{array}{c}\mathrm{PCr} \\
(\mathrm{mg} / \mathrm{dL}) \\
(\mathrm{N}<1.2)\end{array}$ & $\begin{array}{l}\text { IgG4 (mg/dL) } \\
\quad(\mathrm{N}<135)\end{array}$ & $\begin{array}{l}\text { Kidney CT radiological } \\
\text { findings }\end{array}$ & Immunosuppressive therapy & Ref \\
\hline 1 & $\mathrm{M} / 70$ & 18 & 2.3 & 550 & ND & MDZ (pulse), PDZ (30) & [16] \\
\hline 2 & $\mathrm{M} / 64$ & 1 & 3.9 & 665 & ND & MDZ (32) & [17] \\
\hline 3 & $\mathrm{M} / 67$ & 72 & 3.4 & 2,125 & ND & PDZ (40) & [37] \\
\hline 4 & $\mathrm{M} / 52$ & 0 & 0.74 & ND & Bilateral nodules & PDZ (40), AZA (75) & [35] \\
\hline 5 & $\mathrm{M} / 61$ & 96 & 1.09 & 730 & Unilateral LDM* & PDZ (60) & [38] \\
\hline 6 & $\mathrm{M} / 52$ & ND & ND & ND & Bilateral nodules & CST (?) & [39] \\
\hline 7 & $\mathrm{~F} / 58$ & 9 & 2.2 & 352 & Bilateral nodules & PDZ (40) & [51] \\
\hline 8 & $\mathrm{M} / 66$ & 12 & 1.76 & 1,830 & ND & PDZ (?) & [34] \\
\hline 9 & $\mathrm{~F} / 68$ & 72 & 3.6 & 2,350 & Bilateral swelling & PDZ (30) & [40] \\
\hline 10 & $\mathrm{M} / 69$ & 12 & 2.5 & 221 & ND & PDZ (30) & [40] \\
\hline 11 & $\mathrm{M} / 55$ & ND & 0.69 & 377 & ND & CST (?) & [41] \\
\hline 12 & $\mathrm{M} / 59$ & ND & 1.16 & 282 & Right UHN & CST (?) & [42] \\
\hline 13 & $\mathrm{M} / 76$ & 0 & 0.74 & 1,030 & Bilateral nodules & CST (?) & [42] \\
\hline 14 & $\mathrm{M} / 55$ & 0 & 2.1 & 1,780 & ND & CST (?) & [42] \\
\hline 15 & $\mathrm{M} / 71$ & ND & 1.0 & 1,030 & Bilateral nodules & ND & [43] \\
\hline 16 & $\mathrm{M} / 57$ & ND & 1.0 & ND & Unilateral LDM* & ND & [43] \\
\hline 17 & $\mathrm{~F} / 68$ & 24 & 1.6 & 1,295 & Bilateral nodules & ND & [43] \\
\hline 18 & $\mathrm{M} / 78$ & 24 & 3.0 & ND & ND & ND & [43] \\
\hline 19 & $\mathrm{M} / 80$ & 0 & 1.4 & 660 & Bilateral atrophy & PDZ (40) & [33] \\
\hline 20 & $\mathrm{M} / 64$ & ND & 4.8 & 617 & Normal & PDZ (40) & [44] \\
\hline 21 & $\mathrm{M} / 50$ & ND & 0.7 & ND & ND & ND & [45] \\
\hline 22 & $\mathrm{M} / 58$ & ND & 1.2 & ND & ND & ND & [45] \\
\hline 23 & $\mathrm{M} / 72$ & ND & ND & $\uparrow$ & Mass & ND & [46] \\
\hline 24 & $\mathrm{M} / 72$ & ND & 4.2 & $\uparrow$ & Mass multiple & PDZ(?) & [46] \\
\hline 25 & $\mathrm{M} / 84$ & ND & 5.7 & $\uparrow$ & Normal & $\mathrm{PDZ}(?) / \mathrm{MMF} / \mathrm{HD}$ & [46] \\
\hline 26 & $\mathrm{M} / 66$ & ND & 1.1 & Normal & Mass & PDZ(?)/MMF(?) & [46] \\
\hline 27 & $\mathrm{M} / 69$ & ND & 3.8 & Normal & ND & PDZ(?) & [46] \\
\hline 28 & $\mathrm{M} / 74$ & ND & 6.3 & Normal & ND & PDZ(?) & [46] \\
\hline 29 & $\mathrm{~F} / 59$ & ND & 2.6 & $\uparrow$ & Bilateral nodules & PDZ(?)/MMF(?) & [46] \\
\hline 30 & $\mathrm{M} / 63$ & ND & 1.4 & Normal & Mass & SURGERY & {$[46]$} \\
\hline 31 & $\mathrm{M} / 57$ & ND & $\uparrow$ & ND & ND & ND & [46] \\
\hline 32 & $\mathrm{M} / 72$ & ND & 3.2 & ND & ND & PDZ(?) & [46] \\
\hline 33 & $\mathrm{M} / 71$ & ND & 1,1 & $\uparrow$ & Bilateral nodules & NO & [46] \\
\hline 34 & $\mathrm{M} / 57$ & ND & Normal & ND & LDM & ND & [46] \\
\hline 35 & $\mathrm{M} / 68$ & ND & 1.1 & $\uparrow$ & Bilateral LDM & NO & [46] \\
\hline 36 & $\mathrm{M} / 78$ & ND & 3.0 & $\uparrow$ & Normal & PDZ(?) & [46] \\
\hline 37 & $\mathrm{M} / 70$ & ND & 0.9 & 623 & ND & ND & [56] \\
\hline 38 & $\mathrm{M} / 59$ & ND & 1.1 & 734 & ND & ND & [56] \\
\hline 39 & $\mathrm{M} / 63$ & ND & 1.2 & 408 & ND & ND & [56] \\
\hline 40 & $\mathrm{M} / 55$ & ND & 2.1 & 1,780 & ND & ND & [56] \\
\hline 41 & $\mathrm{M} / 69$ & ND & 2.36 & 1,340 & ND & ND & [56] \\
\hline 42 & $\mathrm{M} / 80$ & ND & 1.6 & 660 & ND & ND & {$[56]$} \\
\hline 44 & $\mathrm{M} / 69$ & ND & 7.26 & 1,120 & ND & ND & [56] \\
\hline 45 & $\mathrm{M} / 78$ & ND & 6.17 & 1,860 & ND & ND & [56] \\
\hline 46 & $\mathrm{M} / 50$ & 0 & & Normal & Swelling & PDZ & [57] \\
\hline 47 & $\mathrm{M} / 80$ & 4 & 0.9 & 1,350 & Normal & PDZ / Mizoribine & [47] \\
\hline 48 & $\mathrm{M} / 16$ & 72 & ND & $\uparrow$ & Abnormal & PDZ(?) & [49] \\
\hline 49 & $\mathrm{M} / 65$ & 24 & 1.4 & 526 & Bilateral LDM & $\operatorname{MDZ}(32) / \operatorname{AZA}(150)$ & [18] \\
\hline 50 & $\mathrm{M} / 47$ & 24 & 0.9 & 310 & Normal & MDZ (64) & [48] \\
\hline
\end{tabular}

Abbreviations: AIP: autoimmune pancreatitis; AZA: azathioprine; CT: computed tomography; CST: corticosteroids; F: female; HD: hemodialysis; LDM: low density mass; M: male MDZ: methylprednisolone; ND: not done; PDZ: prednisolone; TIN: tubulointerstitial nephritis UHN: ureterohydronephrosis; ( ): daily dose of immunosuppressive drugs expressed in mg; $*$ : magnetic resonance cholangiopancreatography 
Agnieszka AP (2016) Atypical presentation of IgG4-related autoimmune pancreatitis - be awake to early detecting subsequent renal involvement: case report and literature review

concomitant membranous or membranoproliferative glomerulopathy in some cases $[17,33,36,37,45,47,50]$. One or both kidneys could be affected as displayed by radiological explorations $[35,38,42,43]$. Poorly enhancing bilateral renal lesions detected by MRI investigation was reported only in two cases $[35,51]$. The progressive alteration of renal function in the case reported here is timely related to the development of hypointense cortical nodules in both kidneys detected by abdominal CT accordingly to the previous reports [39,42,51,52]. Hypo-intense renal lesions an abdominal CT could resolve with corticotherapy or not. The type of immunosuppressive therapy was known in 27 of the 50 cases. Methyprednisolone was prescribed intravenously $(1 \mathrm{mg} / \mathrm{kg} /$ day $)$ or orally (32 mg/day) but prednisolone (PDZ) was given orally (30-60 $\mathrm{mg}$ /day). Normalization of renal function was observed in the majority of cases. Corticoresistance was reported in two patients with severe renal insufficiency, attributed to marked tubular atrophy and intense interstitial fibrosis at the time of the diagnosis [33,44]. Azathoprine (AZA) resulted in stabilization of PCr level after degressive dose of PDZ [35].

This review of the literature indicates that renal involvement must be checked in all IgG4-related AIP. Detailed clinical evaluation for evidence of organ involvement associated or no with organ function failure as well as evaluation for malignancy is required both at first presentation and during long-term follow-up of AIP [53]. Our case demonstrate that during the follow-up of AIP type 1, DW-MRI imaging detected IgG4-related kidney disease early before clinical or biological manifestations of renal dysfunction despite normal contrast-enhanced CT and ${ }^{18} \mathrm{FDG}-\mathrm{PET} / \mathrm{CT}$ imaging. We previously reported that DW-MRI appears as a non-nephrotoxic prompt tool for subclinical assessment of acute IgG4-TIN $[48,54]$. Early referral to the nephrologists should be considered in all patients with AIP type 1 presenting signs of radiological involvement of the kidney and/or increase in PCr levels associated or no with abnormality of urinary sediment (proteinuria). Indeed, in case, in which the estimated glomerular filtration rate has already decreased to less than $60 \mathrm{~mL} /$ $\mathrm{min} / 1,73 \mathrm{~m}^{2}$ before treatment, only partial recovery of renal function has been observed [11]. Early initiation of corticoids therapy has been reported to prevent renal interstitial fibrosis only to some extent [55]. Renal biopsy guided by radiological abnormality, especially DW-MRI imaging has been reported to enhance the probability to obtain a representative material of renal tissue for correct diagnosis [54].

In conclusion, in a patient with a suspicion of AIP and/or with sclerosing cholangitis, presenting an abnormality on DW-MRI renal imaging the risk of IgG4-related TIN should be taken into account indicating early referral to nephrologist independently of PCr level to prevent progressive kidney damage. Renal biopsy is needed to early confirm IgG4-related kidney involvement and to establish the optimal immunosuppressive therapy. The interest of DW-MRI guided biopsy of hypointense renal nodule as a radiological marker of early IgG4related TIN before PCr raise merit to be evaluated in further study.

\section{Conflict of interest}

The authors declare that there is no conflict of interest regarding the publication of this paper.

\section{Acknowledgments}

We thank Mr S. Deferme for his critical reading of this manuscript.

\section{References}

1. Finkelberg DL, Sahani D, Deshpande V, Brugge WR (2006) Autoimmune pancreatitis.
N Engl J Med 355: 2670-2676. [Crossref]

2. Pickartz T, Mayerle J, Lerch MM (2007) Autoimmune pancreatitis. Nat Clin Pract Gastroenterol Hepatol 4: 314-323. [Crossref]

3. Sugumar A, Chari ST (2009) Distinguishing pancreatic cancer from autoimmune pancreatitis: a comparison of two strategies. Clin Gastroenterol Hepatol 7: S59-S62. [Crossref]

4. Robison LS, Canon CL, Varadarajulu S, Eloubeidi MA, et al. (2011) Autoimmune pancreatitis mimicking pancreatic cancer. J Hepatobiliary Pancreat Sci 18: 162-169. [Crossref]

5. Kamisawa T, Chen PY, Tu Y, Nakajima H, Egawa N (2006) Pancreatic cancer with a high serum IgG4 concentration. World J Gastroenterol 12: 6225-6228. [Crossref]

6. Franchello A, Gonella F, Campra D, Limerutti G, Bruno M, et al. (2014) A rare case of IgG4-related systemic disease manifesting with pancreatic head mass mimicking borderline resectable cancer. Int J Surg Case Rep 5: 1095-1097. [Crossref]

7. Shimosegawa T, Chari ST, Frulloni L, Kamisawa T, Kawa S, et al. (2011) International consensus diagnostic criteria for autoimmune pancreatitis: guidelines of the International Association of Pancreatology. Pancreas 40: 352-358. [Crossref]

8. Chari ST, Smyrk TC, Levy MJ, Topazian MD, Takahashi N, et al. (2006) Diagnosis of autoimmune pancreatitis: the Mayo Clinic experience. Clin Gastroenterol Hepatol 4: 1010-1016. [Crossref]

9. Kamisawa T, Shimosegawa T, Okazaki K, Nishino T, Watanabe H, et al. (2009) Standard steroid treatment for autoimmune pancreatitis. Gut 58:1504-1507. [Crossref]

10. Kim HM, Chung MJ, Chung JB (2010) Remission and relapse of autoimmune pancreatitis: focusing on corticosteroid treatment. Pancreas 39: 555-560. [Crossref]

11. Vasaitis L (2016) IgG4-related disease: A relatively new concept for clinicians. Eur J Intern Med 27: 1-9. [Crossref]

12. Kamisawa T, Funata N, Hayashi Y (2004) Lymphoplasmacytic sclerosing pancreatitis is a pancreatic lesion of IgG4-related systemic disease. Am J Surg Pathol 28: 1114.

13. Sato Y, Notohara K, Kojima M, Takata K, Masaki Y, et al. (2010) IgG4-related disease: historical overview and pathology of hematological disorders. Pathol Int 60: 247-258. [Crossref]

14. Yamamoto M, Takahashi H, Shinomura Y: [IgG4-related systemic disease/systemic IgG4-related disease]. Rinsho Byori 2010;58:454-465.

15. Stone JH, Zen Y, Deshpande V (2012) IgG4-related disease. N Engl J Med 366: 539551. [Crossref]

16. Takeda S, Haratake J, Kasai T, Takaeda C, Takazakura E, et al. (2004) IgG4-associated idiopathic tubulointerstitial nephritis complicating autoimmune pancreatitis. Nephrol Dial Transplant 19: 474-476.

17. Uchiyama-Tanaka Y, Mori Y, Kimura T, Sonomura K, Umemura S, Kishimoto N, et al. (2004) Acute tubulointerstitial nephritis associated with autoimmune-related pancreatitis. Am J Kidney Dis 43: e18-e25. [Crossref]

18. Pozdzik AA, Brocheriou I, Demetter P, Matos C, Delhaye M, et al. (2012) Azathioprine as successful maintenance therapy in IgG4-related tubulointerstitial nephritis. Clin Kidney J 5: 225-228. [Crossref]

19. Kanno A, Masamune A, Okazaki K, Kamisawa T, Kawa S, et al. (2015) Nationwide epidemiological survey of autoimmune pancreatitis in Japan in 2011. Pancreas 44: 535-539. [Crossref]

20. Nakatani K, Nakamoto Y, Togashi K (2012) Utility of FDG PET/CT in IgG4-related systemic disease. Clin Radiol 67: 297-305. [Crossref]

21. Courcet E, Beltjens F, Charon-Barra C, Guy F, Orry D, Ghiringhelli F, Arnould L: [An IgG4-related pancreatitis mimicking an adenocarcinoma: A case report]. Ann Pathol 2015;35:511-514.

22. Cao Z, Tian R, Zhang T, Zhao Y (2015) Localized Autoimmune Pancreatitis: Report of a Case Clinically Mimicking Pancreatic Cancer and a Literature Review. Medicine (Baltimore) 94: e1656.

23. Crosara S, D’Onofrio M, De RR, Demozzi E, Canestrini S, et al. (2014) Autoimmune pancreatitis: Multimodality non-invasive imaging diagnosis. World J Gastroenterol 20: 16881-16890. [Crossref]

24. Asbun HJ, Conlon K, Fernandez-Cruz L, Friess H, Shrikhande SV, et al. (2014) When to perform a pancreatoduodenectomy in the absence of positive histology? A consensus statement by the International Study Group of Pancreatic Surgery. Surgery 155: 887892. [Crossref] 
Agnieszka AP (2016) Atypical presentation of IgG4-related autoimmune pancreatitis - be awake to early detecting subsequent renal involvement: case report and literature review

25. Umehara H, Okazaki K, Masaki Y, Kawano M, Yamamoto M, et al. (2012) Comprehensive diagnostic criteria for IgG4-related disease (IgG4-RD), 2011. Mod Rheumatol 22: 21-30. [Crossref]

26. Matsubayashi H, Kakushima N, Takizawa K, Tanaka M, Imai K, et al. (2014) Diagnosis of autoimmune pancreatitis. World J Gastroenterol 20: 16559-16569. [Crossref]

27. Hubers LM, Maillette de Buy Wenniger LJ, Doorenspleet ME, Klarenbeek PL, Verheij $\mathrm{J}$, et al. (2015) IgG4-associated cholangitis: a comprehensive review. Clin Rev Allergy Immunol 48: 198-206. [Crossref]

28. Pezzilli R, Pagano N (2014) Pathophysiology of autoimmune pancreatitis. World $J$ Gastrointest Pathophysiol 5: 11-17. [Crossref]

29. Hart PA, Kamisawa T, Brugge WR, Chung JB, Culver EL, et al. (2013) Long-term outcomes of autoimmune pancreatitis: a multicentre, international analysis. Gut 62: 1771-1776.

30. Kamisawa T, Okamoto A, Wakabayashi T, Watanabe H, Sawabu N (2008) Appropriate steroid therapy for autoimmune pancreatitis based on long-term outcome. Scand J Gastroenterol 43: 609-613. [Crossref]

31. Kamisawa T, Tu Y, Egawa N, Tsuruta K, Okamoto A (2008) A new diagnostic endoscopic tool for autoimmune pancreatitis. Gastrointest Endosc 68: 358-361.

32. Kamisawa T, Okazaki K, Kawa S, Shimosegawa T, Tanaka M (2010) Japanese consensus guidelines for management of autoimmune pancreatitis: III. Treatment and prognosis of AIP. J Gastroenterol 45: 471-477. [Crossref]

33. Morimoto J, Hasegawa Y, Fukushima H, Uesugi N, Hisano S, et al. (2009) Membranoproliferative glomerulonephritis-like glomerular disease and concurren tubulointerstitial nephritis complicating IgG4-related autoimmune pancreatitis. Intern Med 48: 157-162. [Crossref]

34. Nishi H, Tojo A, Onozato ML, Jimbo R, Nangaku M, et al. (2007) Anti-carbonic anhydrase II antibody in autoimmune pancreatitis and tubulointerstitial nephritis. Nephrol Dial Transplant 22: 1273-1275. [Crossref]

35. Rudmik L, Trpkov K, Nash C, Kinnear S, Falck V, et al. (2006) Autoimmune pancreatitis associated with renal lesions mimicking metastatic tumours. CMAJ 175: 367-369. [Crossref]

36. Saeki T, Imai N, Ito T, Yamazaki H, Nishi S, et al. (2009) Membranous nephropathy associated with IgG4-related systemic disease and without autoimmune pancreatitis. Clin Nephrol 71: 173-178. [Crossref]

37. Watson SJ, Jenkins DA, Bellamy CO (2006) Nephropathy in IgG4-related systemic disease. Am J Surg Pathol 30: 1472-1477. [Crossref]

38. Saeki T, Saito A, Hiura T, Yamazaki H, Emura I, et al. (2006) Lymphoplasmacytic infiltration of multiple organs with immunoreactivity for IgG4: IgG4-related systemic disease. Intern Med 45: 163-167.

39. Nakamura H, Wada H, Origuchi T, Kawakami A, Taura N, et al. (2006) A case of IgG4related autoimmune disease with multiple organ involvement. Scand J Rheumatol 35: 69-71. [Crossref]

40. Yoneda K, Murata K, Katayama K, Ishikawa E, Fuke H, et al. (2007) Tubulointerstitial nephritis associated with IgG4-related autoimmune disease. Am J Kidney Dis 50: 455462. [Crossref]

41. Saeki T, Saito A, Yamazaki H, Emura I, Imai N, et al. (2007) Tubulointerstitia nephritis associated with IgG4-related systemic disease. Clin Exp Nephrol 11: 168-173.

42. Saeki T, Nishi S, Ito T, Yamazaki H, Miyamura S, et al. (2007) Renal lesions in IgG4related systemic disease. Intern Med 46: 1365-1371. [Crossref]
43. Cornell LD, Chicano SL, Deshpande V, Collins AB, et al. (2007) Pseudotumors due to IgG4 immune-complex tubulointerstitial nephritis associated with autoimmune pancreatocentric disease. Am J Surg Pathol 31: 1586-1597. [Crossref]

44. Hill P, Russell P, Sammartino C, Wiggins K, Dwyer K (2009) Acute kidney injury and proteinuria in a patient with diabetes and a submandibular mass. Am J Kidney Dis 54 375-380. [Crossref]

45. Nakashima H, Miyake K, Moriyama M, Tanaka A, (2010) An amplification of IL-10 and TGF-beta in patients with IgG4-related tubulointerstitial nephritis. Clin Nephrol 73: 385-391. [Crossref]

46. Raissian Y, Nasr SH, Larsen CP, Colvin RB, Smyrk TC, et al. (2011) Diagnosis of IgG4-related tubulointerstitial nephritis. J Am Soc Nephrol 22: 1343-1352. [Crossref]

47. Miyata KN, Kihira H, Haneda M, Nishio Y (2014) IgG4-Related Tubulointerstitia Nephritis Associated with Membranous Nephropathy in Two Patients: Remission after Administering a Combination of Steroid and Mizoribine. Case Rep Nephrol 2014: 678538 .

48. Pozdzik AA, Matos C, Rorive S, Brocheriou I, Van GD (2013) Diffusion-weighted magnetic resonance imaging as a new diagnostic tool of subclinical IgG4-related acute tubulointerstitial nephritis. Clin Kidney J 6: 235-237. [Crossref]

49. Huelsen A, Bailey W, Whitehead M, Chalmers-Watson T (2012) Autoimmune pancreatitis and primary sclerosing cholangitis in a 16-year-old boy with inflammatory bowel disease. Clin J Gastroenterol 5: 131-135.

50. Katano K, Hayatsu Y, Matsuda T, Miyazaki R, Yamada K, et al. (2007) Endocapillary proliferative glomerulonephritis with crescent formation and concurren tubulointerstitial nephritis complicating retroperitoneal fibrosis with a high serum level of IgG4. Clin Nephrol 68: 308-314. [Crossref]

51. Murashima M, Tomaszewski J, Glickman JD (2007) Chronic tubulointerstitial nephritis presenting as multiple renal nodules and pancreatic insufficiency. Am J Kidney Dis 49 e7-10. [Crossref]

52. Triantopoulou C, Malachias G, Maniatis P, Anastopoulos J, Siafas I, et al. (2010) Renal lesions associated with autoimmune pancreatitis: CT findings. Acta Radiol 51: 702707. [crosssref]

53. Huggett MT, Culver EL, Kumar M, Hurst JM, Rodriguez-Justo M, Chapman MH, Johnson GJ, Pereira SP, Chapman RW, Webster GJ, Barnes E (2014) Type 1 autoimmune pancreatitis and IgG4-related sclerosing cholangitis is associated with extrapancreatic organ failure, malignancy, and mortality in a prospective UK cohort. Am J Gastroenterol 109: 1675-1683. [Crossref]

54. Pozdzik AA, Matos C, Rorive S, Brocheriou I, Delhaye M (2014) Diffusion-weighted magnetic resonance imaging: a non-nephrotoxic prompt assessment of kidney involvement in IgG4-related disease. Kidney Int 85: 981. [Crossref]

55. Mizushima I, Yamada K, Fujii H, Inoue D, Umehara H, et al, (2012) Clinica and histological changes associated with corticosteroid therapy in IgG4-related tubulointerstitial nephritis. Mod Rheumatol 22: 859-870.

56. Kawano M, Mizushima I, Yamaguchi Y, Imai N, Nakashima H, et al. (2012) Immunohistochemical Characteristics of IgG4-Related Tubulointerstitial Nephritis: Detailed Analysis of 20 Japanese Cases. Int J Rheumatol 2012: 609795. [Crossref]

57. Nakano E, Kanno A, Masamune A, Yoshida N, Hongo S, et al. (2015) IgG4-unrelated type 1 autoimmune pancreatitis. World J Gastroenterol 21: 9808-9816. [Crossref]

58. Pozdzik AA, Berton A, Schmeiser HH, Missoum W, Decaestecker C, et al. (2010) Aristolochic acid nephropathy revisited: a place for innate and adaptive immunity? Histopathology 56: 449-463.

Copyright: (C2016 Agnieszka AP. This is an open-access article distributed under the terms of the Creative Commons Attribution License, which permits unrestricted use, distribution, and reproduction in any medium, provided the original author and source are credited. 